This item was submitted to Loughborough's Research Repository by the author.

Items in Figshare are protected by copyright, with all rights reserved, unless otherwise indicated.

\title{
Surface modification of chromatography adsorbents by low temperature low pressure plasma
}

\section{PLEASE CITE THE PUBLISHED VERSION}

http://dx.doi.org/10.1016/j.chroma.2010.08.069

\section{PUBLISHER}

(C) Elsevier

VERSION

AM (Accepted Manuscript)

LICENCE

CC BY-NC-ND 4.0

\section{REPOSITORY RECORD}

Arpanaei, A., B. Winther-Jensen, Eirini Theodosiou, P. Kingshott, T.J. Hobley, and Owen R.T. Thomas. 2013. "Surface Modification of Chromatography Adsorbents by Low Temperature Low Pressure Plasma". figshare. https://hdl.handle.net/2134/12019. 
This item was submitted to Loughborough's Institutional Repository (https://dspace.lboro.ac.uk/) by the author and is made available under the following Creative Commons Licence conditions.

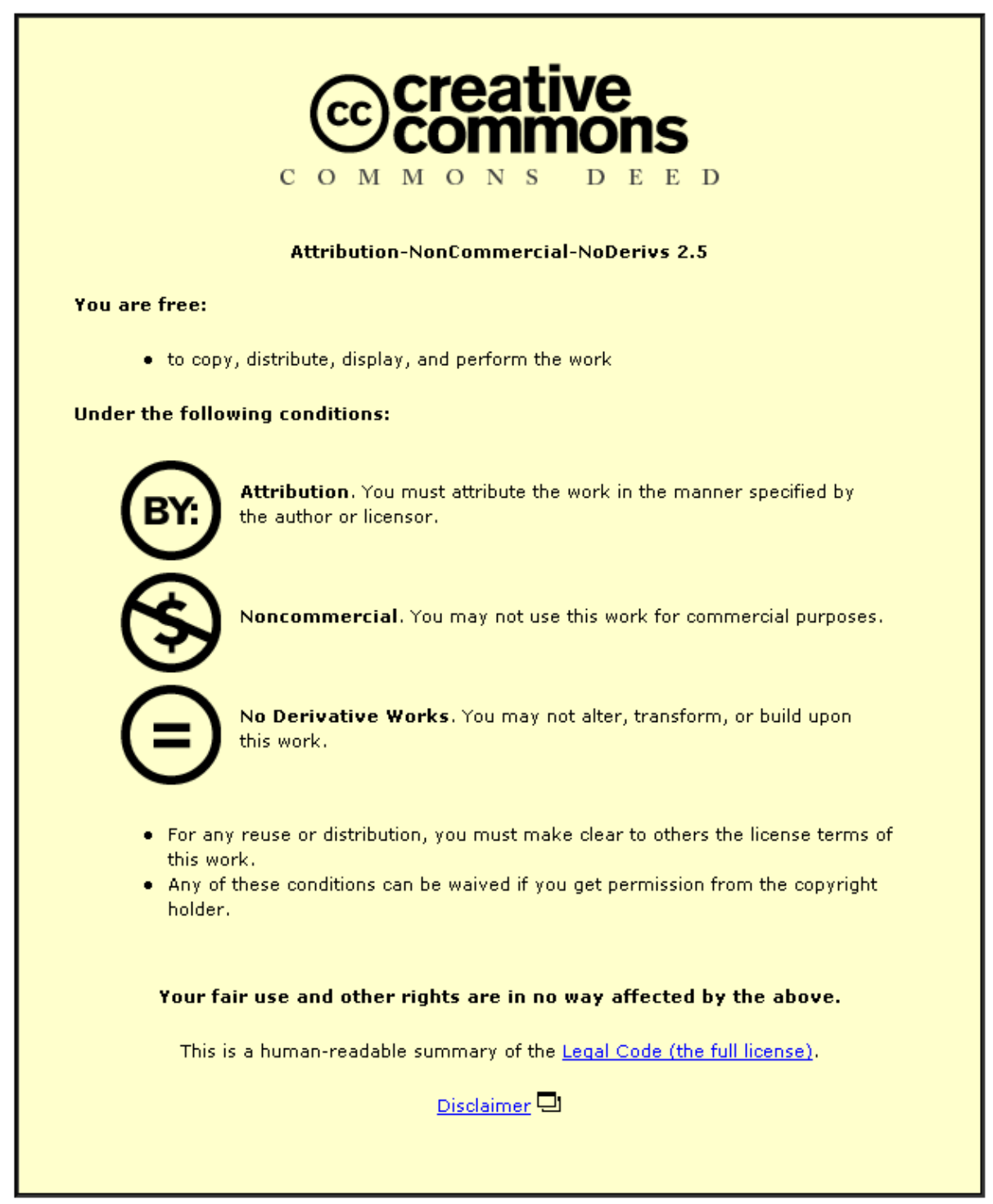

For the full text of this licence, please go to: http://creativecommons.org/licenses/by-nc-nd/2.5/ 


\title{
Surface modification of chromatography adsorbents by low temperature low pressure plasma
}

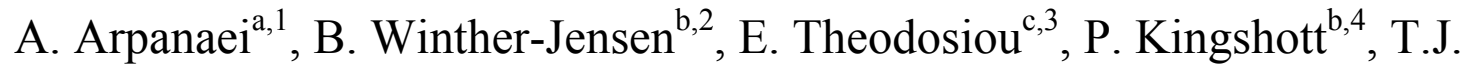 \\ 5 Hobley $^{\mathrm{a}}$, O.R.T. Thomas ${ }^{\mathrm{c}, *}$
}

${ }^{\mathrm{a} C e n t e r}$ for Microbial Biotechnology, Building 223, Institute for Systems Biology, Technical University of Denmark, DK-2800 Lyngby, Denmark,

${ }^{\mathrm{b}}$ The Danish Polymer Centre, Risø National Laboratory, DK-4000, Denmark

$10{ }^{\mathrm{c}}$ School of Chemical Engineering, College of Engineering and Physical Sciences, The University of Birmingham, Edgbaston, B15 2TT, UK

*Corresponding author at: Tel.: +44 1214145278, fax: +44 1214145377, E-mail address: o.r.t.thomas@bham.ac.uk (O.R.T. Thomas)

15

${ }^{1}$ Present address: Department of Industrial and Environmental Biotechnology, National Institute of Genetic Engineering and Biotechnology, P.O. Box 14965/161, Tehran, Iran

${ }^{2}$ Present address: Department of Material Engineering, Monash University, Clayton, 380020 Victoria, Australia

${ }^{3}$ Present address: Department of Chemical Engineering, Loughborough University, Leicestershire, LE11 3TU, UK

${ }^{4}$ Present address: Interdisciplinary Nanoscience Center (iNANO), The University of Aarhus, Ny Munkegade, 8000 Aarhus C, Denmark 


\section{Abstract:}

In this study we show how low temperature glow discharge plasma can be used to prepare bilayered chromatography adsorbents with non-adsorptive exteriors. The commercial strong anion exchange expanded bed chromatography matrix, Q HyperZ, was treated with plasmas in one of two general ways. Using a purpose-designed rotating reactor, plasmas were employed to either: (i) remove anion exchange ligands at or close to the exterior surface of Q HyperZ, and replace them with polar oxygen containing functions ('plasma etching and oxidation'); or (ii) bury the same surface exposed ligands beneath thin polymer coatings ('plasma polymerization coating') using appropriate monomers (vinyl acetate, vinyl pyrrolidone, safrole) and argon as the carrier gas. X-ray photoelectron spectroscopy analysis (first $\sim 10 \mathrm{~nm}$ depth) of Q HyperZ before and after the various plasma treatments confirmed that substantial changes to the elemental composition of Q HyperZ's exterior had been inflicted in all cases. The atomic percent changes in carbon, nitrogen, oxygen, yttrium and zirconium observed after being exposed to air plasma etching were entirely consistent with: the removal of pendant Q (trimethylammonium) functions; increased exposure of the underlying yttriumstabilised zirconia shell; and introduction of hydroxyl and carbonyl functions. Following plasma polymerization treatments (with all three monomers tested), the increased atomic percent levels of carbon and parallel drops in nitrogen, yttrium and zirconium provided clear evidence that thin polymer coats had been created at the exteriors of Q HyperZ adsorbent particles. No changes in adsorbent size and surface morphology, nor any evidence of plasmainduced damage could be discerned from scanning electron micrographs, light micrographs and measurements of particle size distributions following $3 \mathrm{~h}$ exposure to air $(220 \mathrm{~V} ; 35.8 \mathrm{~W}$ $\left.\mathrm{L}^{-1}\right)$ or 'vinyl acetate/argon' $\left(170 \mathrm{~V} ; 16.5 \mathrm{~W} \mathrm{~L}^{-1}\right)$ plasmas. Losses in bulk chloride exchange capacity before and after exposure to plasmas enabled effective modification depths within hydrated Q HyperZ adsorbent particles to be calculated as 0.2 to $1.2 \mu \mathrm{m}$, depending on the conditions applied. The depth of plasma induced alteration was strongly influenced by the power input and size of the treated batch, i.e. dropping the power or increasing the batch size resulted in reduced plasma penetration and therefore shallower modification. The selectivity of 'surface versus core' modification imparted to Q HyperZ by the various plasma treatments was evaluated in static and dynamic binding studies employing appropriate probes, i.e. plasmid DNA, sonicated calf thymus DNA and bovine serum albumin. In static binding studies performed with adsorbents that had been exposed to plasmas at the $5 \mathrm{~g}$ scale $(25 \mathrm{~g}$ per 
litre of plasma reactor), the highest 'surface/core' modification selectivity was observed for Q HyperZ that had been subjected to $3 \mathrm{~h}$ of air plasma etching at $220 \mathrm{~V}\left(35.8 \mathrm{~W} \mathrm{~L}^{-1}\right)$. This treatment removed $\sim 53 \%$ of 'surface' DNA binding at the expense of a $9.3 \%$ loss in 'core' protein binding. Even more impressive results were obtained in dynamic expanded bed 5 adsorption studies conducted with Q HyperZ adsorbents that had been treated with air $(220 \mathrm{~V}$, $3 \mathrm{~h})$ and 'vinyl acetate/argon' $(170 \mathrm{~V}, 3 \mathrm{~h})$ plasmas at $10.5 \mathrm{~g}$ scale $(52.5 \mathrm{~g}$ per litre of plasma reactor). Following both plasma treatments: the $10 \%$ breakthrough capacities of the modified Q HyperZ adsorbents towards 'surface' binding DNA probes dropped very significantly (30 85\%); the DNA induced inter-particle cross-linking and contraction of expanded beds 10 observed during application of sonicated DNA on native Q HyperZ was completely eradicated; but the 'core' protein binding performance remained unchanged $c f$. that of the native Q HyperZ starting material.

Keywords: Anti-fouling; Expanded bed adsorption; Ion exchange; Non-adsorptive surfaces; 15 Plasma etching / polymerization; Protein and plasmid DNA separation; Size exclusion; Support cross-linking 


\section{Introduction}

Preparative chromatography has been a fundamental unit operation for the pharmaceutical sector for many decades and plays an absolutely pivotal role within biopharmaceutical downstream processing [1-3]. Since Peterson and Sobers prepared cellulose based ion exchangers for the separation of proteins in the mid 1950s [1], chromatographic packing materials for preparative protein separation have been continuously improved with respect to large scale operation, resolving power, separation efficiency, selectivity, and sorption capacity [1-4]. However, though today's chromatography materials are unquestionably superior to their forerunners, in some ways their development has stood still. For example, the basic design and expected tasks have changed surprising little over the past 50 years, with most still performing just a single function. The explosion in new high-level expression systems for the production of recombinant proteins has reduced upstream processing costs to the point where concentration and purification operations, i.e. downstream processing, now dominates the overall manufacturing cost for many protein therapeutics [3-6]. Yet, though this situation creates a great incentive to advance more efficient downstream processing technologies and processes, especially for future products, the reality is that advances in downstream processing over the past decade lag far behind those made in upstream processing over the same period, and further, that process chromatography is increasingly viewed as a serious bottleneck within biopharmaceutical manufacturing [3-6].

Among the growing list of challenges facing the development of new improved chromatographic materials for existing and future products are: rocketing product titres; increasing size and complexity of emerging bio-products; escalating cost of goods and waste generation; and increasing competition from alternative techniques/formats. It is difficult to envisage effective solutions to these coming from continued incremental improvement of conventional mono-functional chromatography adsorbent matrices, i.e. materials performing just a single function. Conversely, the concept of multi-functional media featuring two or more distinct functional regions spatially separated from one another within the same support bead, affords attractive solutions, to at least some of these issues, to be envisaged. The present study concerns the simplest multi-layered multi-functional support design one can envisage, namely one featuring just two differently functionalised layers - an inert outer size excluding layer and inner ion exchange functionalised core. The benefits of bi-layered size exclusion 
chromatography - ion exchange chromatography (SEC-IEC) beaded support designs have been clearly demonstrated in the context of 'nanoplex' purification [7,8], fluidised bed separation of organic acids [9, 10] and expanded bed adsorption of proteins [11, 12]. The important findings from these studies, inherent flaws in the methods employed thus far to manufacture bi-layered SEC-IEC hybrids, and identification of a simple and effective solution to the future manufacture of multi-layered multi-functional beaded chromatography matrices, are presented immediately below.

Nanoplexes are a rapidly growing and diverse product grouping characterized by large physical size, fragility, complex surfaces plus chemical similarity to smaller contaminating macromolecular components; important examples include non-viral vector components such as naked plasmid DNA, viral vectors, mega-molecular vaccines and mega-protein complexes [13-15]. Their properties dictate that their efficient large-scale manufacture must follow a very different 'general' path to that established for therapeutic human proteins of much smaller dimensions $[13,16-21]$. Current protocols for the purification of plasmid DNA show heavy reliance on packed bed chromatography - centred on capture by anion exchange (AEC) adsorption, followed by polishing of the salt-eluted fraction by size exclusion chromatography $[16,17,19,21]$. Though ion exchange chromatography has found very widespread use for the large scale purification of antibiotics and protein-based drugs, its application for commercial scale production of plasmid DNA (pDNA) and other nanoplexes is far less attractive [16$19,21]$.

Recently, it has been demonstrated that much greater productivity could be realised if the SEC and AEC operations are 'passively' combined in a single chromatographic operation, employing a new type of multi-functional chromatography material (known as the lid bead) [7, 8]. Starting from an SEC matrix with a nucleic acid exclusion limit of $1000 \mathrm{bp}$, Gustavsson and co-workers [7] made a bi-functional restricted access matrix possessing a positively charged core (to adsorb large amounts of RNA and protein) and an inert outer layer to exclude pDNA from accessing the functionalised bead interior. The creation of the two layers within the matrix was achieved in an ingenious multi-step process, which relied on the use of limiting concentrations of reactants and 'diffusion/reaction' balancing in the second step. However, despite showing considerable promise, the bi-functional materials produced 
did not quite live up to expectations. For example, in tests with plasmid-containing cleared alkaline lysate feedstocks of high ionic strength, the authors noted that in order to prevent pDNA binding, over $30 \%$ of the core's RNA binding capacity had to be sacrificed. Though elegant, the methods of manufacture led to three linked problems, namely insufficient control over the: (i) thickness and (ii) inertness of the outer size excluding layer; and (iii) boundary 'definition' between the different zones within the support.

A SEC-IEC design is equally attractive for expanded bed adsorption (EBA), a type of fluidised bed chromatography, originally conceived as a generic solution for combining solidliquid separation with initial chromatographic capture and purification [22-24]. Despite rapid initial successes, the progress of EBA into industry has been slow, and confidence in the technique is waning $[25,26]$. Perhaps the greatest technical problem affecting EBA is the physical cross-linking of neighbouring adsorbent particles by biomass or large colloidal molecules (especially nucleic acids) present in crude feedstocks, which leads to gross breakdown/collapse of the structure of the expanded bed and consequent loss of chromatographic performance [18, 25-34]. Attempts to relieve problems of inter-adsorbent particle cross-linking in EBA systems by chemically or mechanically conditioning the crude feedstock prior to application have been at best only partially successful [26, 32, 33]. This is not surprising given that the root of the problem is that the outer surfaces of expanded bed adsorbents, like other beaded chromatographic materials, are populated with functional groups capable of binding both the product of interest and large adsorbent cross-linking contaminants present in crude feedstocks. Commercially available EBA adsorbents are direct descendents of packed bed chromatography matrices employed for the purification of proteins, and since their inception well over a decade ago the design of improved materials has concentrated on improving sorption performance with a view to achieving greater bioprocess intensification. Two general approaches have found favour, i.e. increasing the potential protein loading capacity by raising ligand densities to extreme levels (e.g. GE Heathcare's Xtra Load range of STREAMLINE media), and by manufacturing smaller adsorbent beads with increased specific weight (e.g. Pall's HyperZ adsorbents). Rather than help intensify bioprocesses, both of these actions have in fact resulted in less robust EBA operation with crude feedstocks for which the technique was originally intended [25, 32, 33]. Very little effort has been invested thus far on redesigning expanded bed supports for 'problem-free' use in crude feedstocks. 
Most relevant reports to date have involved very low molecular target species, not globular proteins, and small pored Amberlite anion exchange resins rather than bona fide porous expanded bed supports intended for protein sorption. For example, Daniak and co-workers [9] covalently attached polyacrylic acid onto the exterior surfaces of an oppositely charged Amberlite ion exchange matrix. The polyacrylic acid layer was penetrable by small molecules such as the target, shikimic acid, but not to proteins, and repelled much larger negatively charged yeast cells and cell debris. The authors demonstrated that, unlike the native Amberlite anion exchange matrix, fluidised beds of the polyacrylic acid coated 'cell repelling' version could be successfully employed for direct capture of shikimic acid from industrial fermentation liquors. In related work, Daniak et al. [11] electrostatically adsorbed high molecular weight polyacrylic acid to the exterior of the commercial expanded bed anion exchange adsorbent, STREAMLINE DEAE, and employed the resulting matrix to process biand tri- component mixtures (i.e. 'BSA + lysozyme' and 'BSA + lysozyme + yeast cells'). The adsorbed polyacrylic acid coating proved effective in reducing cell adsorption and preventing bed collapse, and remained bound over the range of low ionic strengths employed (20 $\mathrm{mM}$ Tris/ $\mathrm{HCl}$ supplemented with up to $0.2 \mathrm{M} \mathrm{NaCl}$ ). However, the potential risk of adsorbing oppositely charged contaminating species at the adsorbent's exterior surface under mild operating conditions, makes shielding of adsorbent beads with an oppositely charged layer an unattractive proposition for the recovery of protein targets by EBA. Support for this concern comes from the authors' own observations that, BSA $(\mathrm{pI}=5)$ eluted from polyacrylic acid modified STREAMLINE DEAE, but not from native STREAMLINE DEAE, was contaminated with lysozyme $(\mathrm{pI}=11)$. In other work from the same laboratories, Amberlite anion exchanger beads were shielded with a thin layer of cross-linked agarose $(0.2-1 \% \mathrm{w} / \mathrm{v})$, effectively eliminating binding of E. coli, S. cerevisiae and L. casei without compromising dynamic binding capacity towards lactic acid under fluidised bed operation [10]. Most recently, Jahanshahi and co-workers [12] applied similar methods to laminate commercial (STREAMLINE DEAE, CM HyperZ) and prototype expanded bed support materials with 2\% agarose. These authors made similar claims concerning the benefits of their shielded adsorbents, namely reduction in fouling/inter-particle cross-linking and improved bed stability in a crude particulate containing feedstock $(20 \% \mathrm{w} / \mathrm{v}$ yeast homogenate), plus several more, such as improved washing efficiency, reduced buffer consumption, shorter operating cycle times, improved purity and clarity of eluted target proteins. 
A fundamental problem afflicting the lamination of adsorbents with agarose (or other gel forming polymer) described above, is the difficulty in casting sufficiently thin, uniform, mechanically robust layers around core particles (especially of heterogeneous size), and the resulting implications on bed expansion properties, hydrodynamics, and especially intraparticle mass transfer and dynamic binding capacity. Although Jahanshahi et al. [12] employed a more sophisticated three phase emulsification manufacturing process than that described by Viloria-Cols and co-workers [10], much thicker agarose coats were cast in their work. Layer thickness was greatest on smaller core particles. After laminating with agarose, the mean particle diameter of the small dense HyperZ matrix was observed to increase from 80 to $115 \mu \mathrm{m}$ (equivalent to an agarose layer depth of $17.5 \mu \mathrm{m}$ ) and the volume of the particle effectively tripled (the original core particle constituted just $34 \%$ of the laminated particle's volume). Intra-particle mass transfer has been shown to be the main parameter affecting dynamic capacity of an EBA adsorbent $[35,36]$. Though not addressed by the authors in their work, the consequences of such thick shielding layers on mass transfer kinetics and dynamic capacity of bi-layered supports are patently clear. It should be noted that the same mass transfer problems (arising from poor control of the thickness of size excluding layers) can be predicted for the 'lid' beads described earlier.

20 The ideal bi-layered SEC-IEC support for application in EBA processes for protein recovery from tricky feedstocks, or for separation of nanoplexes, should possess 'non-stick' exteriors or barriers that are freely accessible to smaller components (proteins, RNA), but not larger entities, such as long chain nucleic acids, cell debris fragments, nanoplexes, etc., and in order not to compromise mass transport and sorption properties, they must also be very thin [25]. To date these criteria have not been met. Unlocking the potential of bi-layered multifunctional chromatography materials urgently requires development of new approaches capable of operating at the nano-scale with respect to the outermost surface, e.g. to generate ultra-thin ligand devoid layers or coatings that bury offending surface groups. 
Plasma $^{1}$ irradiation is a widely recognised and established technology for modifying the surface properties of materials at the 'nano-scale' [37]. The main advantages of plasma treatment of surfaces are: (i) low temperature reactions (i.e. at room temperature); (ii) changes occur to the chemical structure of the surface in a shallow nano-scale layer without changing the bulk properties; (iii) a very wide range of surface modifications are possible; and (iv) low amounts of toxic by-products are formed during the treatment [38]. To conduct a surface modification by plasma, a glow discharge is created in an evacuated vessel refilled by a low pressure gas. Then, radio frequency $(\mathrm{RF})$, microwave (MW), alternating current (AC), or direct current (DC) is used to energize the gas. Surfaces of objects in the vessel come in contact with the plasma and are bombarded by energetic species (e.g. ions, electrons, radicals), which transfer energy to the surface, causing chemical and physical reactions. For example, during an oxygen plasma treatment, the exposed surface is oxidized, and atoms and chemical groups existing on the surface will be replaced by hydroxyl and carbonyl groups [39-42]. Removing molecular or atomic layers on the surface can also be conducted by using 15 plasma etching [38].

Plasma technology has also been used widely for coating of surfaces to make them resistant to bioadhesion (i.e. anti-biofouling) for a variety of very different applications [43-46]. This has been performed by surface graft polymerization coating or polymer deposition in the presence 20 of plasma with or without concurrent surface activation by oxygen, nitrogen or ammonia. The ability to change the characteristics of a given material surface from hydrophobic to hydrophilic or vice versa is another important application of plasma technology. The modification of chromatography supports using plasma methods is, in contrast to membrane materials [43, 47-52], not well documented, and most reports to date have concerned

25 fabrication of restricted access packing materials for analytical separations of small molecules $[53,54]$.

Against the above, in this paper we have investigated whether plasma can be used to create new bi-layered chromatography supports featuring exteriors modified by either etching and 30 oxidation or polymerization coating. A purpose-built plasma reactor was employed in this work, and the chromatographic starting material selected was the strong anion exchange

${ }^{1}$ Plasma is defined as a partially or wholly ionized medium consisting of electrons, ions and possibly neutrals and photons [37]. 
expanded bed adsorbent, Q HyperZ. The materials generated were characterised using X-ray photoelectron spectroscopy, particle sizing, microscopic techniques, chloride exchange assay, and binding studies employing plasmid DNA and sonicated calf thymus DNA as probes for loss in surface binding, and bovine serum albumin to gauge for reductions in core binding.

\section{Experimental}

\subsection{Materials}

The Q HyperZ anion exchange adsorbent (Table 1, Fig. 1) employed in this work was supplied as a gift from Pall Life Sciences (BioSepra SA, Cergy-Saint-Christophe, France), and the size exclusion matrix, Sephacryl S-500 HR was obtained from GE Healthcare Life Sciences (Amersham, United Kingdom). E. coli DH5 $\alpha$ harbouring the 4 kbp plasmid pUG6 [57] was kindly provided by U. Mortensen (Center for Microbial Biotechnology, Technical University of Denmark). Qiagen Plasmid Maxi kits for plasmid purification and GelPilot Plus DNA ladders were purchased from Qiagen GmbH (Hilden, Germany). The monomers, vinyl pyrrolidone ( $>99 \%$, V3409), vinyl acetate (purum grade, $\geq 99.0 \%, 4604)$ and safrole $(\geq 97 \%$, S94652) used during plasma polymerization (see Fig. 2) were supplied by Sigma-Aldrich Chemical Company (Gillingham, UK) as were all other materials including: tryptone (T7293), yeast extract (BioChemika, 92144), sodium chloride (S5886) and ampicillin (BioChemika, anhydrous, 98\%, 10047) used in the cultivation of E. coli cells; ammonium iron (III) sulphate dodecahydrate (SigmaUltra, $\geq 99 \%, F 1668$ ) and mercuric thiocyanate (purum $\geq 99.0 \%, 83374$ ) for the assay of chloride ions; and deoxyribonucleic acid from calf thymus (type I: sodium salt, 'highly polymerized', Premium, D1501), bovine serum albumin (BSA; fraction V powder, $\geq 96 \%$ pure by electrophoresis, A 9647), Tris(hydroxymethyl)aminomethane (crystalline, $\geq 99.9 \%, \mathrm{~T} 1503$ ) and sodium chloride (SigmaUltra, $\geq 99.5 \%$, S7653) employed in static and dynamic binding studies. MilliQ water was used in all experiments.

\subsection{Plasma reactor}

A schematic representation of the custom-made plasma reactor used in this study is shown in Figure 3. The plasma was created in a rotating cylindrical Pyrex chamber with a rounded end

(40 mm diameter $\times 250 \mathrm{~mm}$ length), the exterior of which was coated with a copper/nylon paper to serve as an electrode. The second electrode, fashioned out of a stainless steel bar (7 mm diameter $\times 550 \mathrm{~mm}$ length), was positioned in the middle of the plasma chamber. The 
volume inside the electrodes, i.e. the actual plasma volume, was $0.2 \mathrm{~L}$. During treatment, the plasma chamber was rotated continuously so as to ensure complete exposure of the exterior surfaces of the adsorbents contained within, to the plasma. An electrical field was created within the chamber using a $20 \mathrm{kHz}$ AC generator powered by a standard $0-240 \mathrm{~V}$ variotransformer. For surface etching and oxidation, the oxidation gas was administered into the plasma reactor via valve 2 . The set-up for plasma polymerization was slightly more elaborate; reservoirs for monomer solution and the carrier gas, argon, were connected to the plasma chamber through valves 1,3 , and 4 .

\subsection{Plasma treatments}

\subsubsection{Plasma etching and oxidation}

The rotating plasma reactor (Fig. 3) was operated at room temperature. Portions of Q HyperZ matrix (5 or $10.5 \mathrm{~g}$ powder equivalent to wet settled bed volumes of 2.4 and $5 \mathrm{~mL}$ respectively) were placed in the chamber before removing the air using a vacuum pump and reducing the pressure to below $10 \mathrm{~Pa}$ - a prerequisite for low temperature low pressure glow discharge plasma (an important consequence of reducing the pressure in this way is that any residual water contained within the matrix beads is vaporized). Valve 2 administering oxidation gas (air in this study) was subsequently opened and the pressure inside the plasma chamber was adjusted to $10 \mathrm{~Pa}$. Rotation $(20 \mathrm{rpm})$ of the reactor was then started, the electrodes were connected and plasma was sustained by applying an electric potential of 220 $\mathrm{V}$ and frequency of $20 \mathrm{MHz}$. Visible radiation confirmed that plasma was generated. After 2 or $3 \mathrm{~h}$ of treatment (Table 2), the tumbling was stopped, the power was turned off, the electrodes were disconnected and gas evacuation was ceased. Valve 2 was then opened to allow equilibration to atmospheric pressure, before opening the chamber and recovering the treated beads. Between successive batches, equipment components coming into contact with the plasma and adsorbents were scrupulously cleaned with acetone, ethanol and then MilliQ water, before drying with a hairdryer. Directly after plasma treatment, the adsorbents were washed on a sintered glass Buchner filter funnel under vacuum with water $(40 \mathrm{~mL} / \mathrm{mL}$ adsorbent), $0.1 \mathrm{M} \mathrm{NaOH}(20 \mathrm{~mL} / \mathrm{mL}), 0.1 \mathrm{M} \mathrm{HCl}(20 \mathrm{~mL} / \mathrm{mL}), 20 \%(\mathrm{v} / \mathrm{v})$ ethanol (60 $\mathrm{mL} / \mathrm{mL})$ solutions and again with water $(60 \mathrm{~mL} / \mathrm{mL})$, before finally resuspending in $50 \mathrm{mM}$ Tris-HCl, pH 8 (20 mL/mL) overnight before use. 


\subsubsection{Plasma polymerization}

The procedure used was initially the same as that described above in 2.3 .1 (i.e. 5 or $10.5 \mathrm{~g}$ portions of Q HyperZ were added to the plasma chamber before removing the air inside the chamber using a vacuum pump to reduce the pressure to below $10 \mathrm{~Pa}$ ), but was more complicated thereafter. Valves 1 and 4 were opened to evacuate air within all connecting lines. Once the pressure had begun to decrease, valve 3 was opened completely. When the pressure once again started decreasing, valve 3 was closed to avoid losing monomer. Then, the argon carrier gas flow into the active compound reservoir was initiated, before very slowly opening valve 3 to reach the desired pressure of $15-20 \mathrm{~Pa}$, and adjusting the carrier gas flow rate into the reactor to $0.3 \mathrm{~L} \mathrm{~h}^{-1}$. Immediately thereafter, reactor rotation (20 rpm) was started, before igniting the plasma, and maintaining it $(100-170 \mathrm{~V} ; 20 \mathrm{MHz})$ for $0.5-3 \mathrm{~h}$ (Table 2). After treatment, the carrier gas flow was terminated, valves 3 and 4 were closed, before breaking the vacuum with air, collecting and washing the treated adsorbents as described previously (section 2.3.1).

15

\subsection{Adsorbent characterisation}

Untreated and selected plasma treated Q HyperZ adsorbents were examined by X-ray photoelectron spectroscopy (XPS), scanning electron microscopy (SEM), light microscopy, chemical assay for anion exchange capacity, static binding (section 2.6) and behaviour in expanded beds during application of BSA, pDNA and sDNA containing feedstocks (section 2.7).

XPS elemental analysis of the outermost $\sim 10 \pm 1 \mathrm{~nm}$ thick sub-surface region of adsorbents was examined on a SAGE HR 100 spectrometer (Specs GmbH, Berlin, Germany) using a non-monochromatic $\mathrm{MgK} \alpha \mathrm{X}$-ray source operated at a power of 275 Watts (11 keV and 25 $\mathrm{mA}$ ) and take off angle of $90^{\circ}$ from the surface plane. The pressure in the analysis chamber was always below $1 \times 10^{-7} \mathrm{mbar}$, and the sample exposure time was kept to a minimum in order to prevent x-ray-induced radiation damage. Atomic concentrations of the elements were determined from surface spectra acquired at $100 \mathrm{eV}$ pass energy in the range from 0 to 1100 $\mathrm{eV}$ and were calculated by determining the relevant integral peak intensities using a linear type background. The systematic error is estimated to be in the order of 5-10\%. 
SEM was conducted using a Zeiss DSM-960 scanning electron microscope (Carl Zeiss AG, Oberkochen, Germany). Before the SEM imaging, the samples were coated with a thin layer of palladium/gold to minimize the charging effect and increase image contrast. Adsorbents were also examined using a Nikon Optiphot light microscope (Nikon, Melville, NY, USA)

5 fitted with a Kappa CF-8/1 FMC monochrome video camera (Kappa Opto-electronics GmbH, Gleichen, Germany). Digitized images and particle size distributions were produced with the aid of Image-Pro ${ }^{\circledR}$ Plus software (version 4.1 for Windows ${ }^{\mathrm{TM}}$; Media Cybernetics, Silver Spring, MD, USA).

Protein and DNA contents in samples were determined by UV spectrophotometry $(280 \mathrm{~nm}$ for protein and $260 \mathrm{~nm}$ for DNA) in a Lambda $20 \mathrm{UV}$-VIS spectrophotometer (PerkinElmer Analytical Instruments, Shelton, CT, USA).

Ionic capacity determinations were carried out as described previously [25]. Briefly, this involved incubating 0.5 to $2 \mathrm{~mL}$ portions of each adsorbent with $50 \mathrm{~mL}$ of $2 \mathrm{M} \mathrm{NaCl}$ for $1.5 \mathrm{~h}$ to convert them into the quaternary alkyl ammonium salt form, washing with MilliQ water (3 $\times 50 \mathrm{~mL}$ ) on a glass sinter, before resuspending the drained adsorbents with $50 \mathrm{~mL}$ of $0.1 \mathrm{M}$ $\mathrm{NaOH}$ and mixing for $24 \mathrm{~h}$ to displace bound $\mathrm{Cl}^{-}$ions. The $\mathrm{Cl}^{-}$contents in $1 \mathrm{~mL}$ aliquots of the liquid phase were determined by a colorimetric assay involving mercury (II) thiocyanate and ammonium iron (III) sulphate [58]. In the assay, the displacement of the thiocyanate ion from mercury (II) thiocyanate by $\mathrm{Cl}^{-}$in the presence of $\mathrm{Fe}^{3+}$ results in the formation of a highly coloured iron (III) thiocyanate complex, and the intensity of its colour (read in a spectrophotometer at $460 \mathrm{~nm}$ ) is proportional to the original $\mathrm{Cl}^{-}$concentration.

\subsection{Preparation of DNA containing feedstocks}

Calf thymus DNA was dissolved slowly overnight in $50 \mathrm{mM}$ Tris- $\mathrm{HCl}, \mathrm{pH} 8$, to yield a viscous $2 \mathrm{mg} \mathrm{mL}^{-1}$ solution, before sonicating on ice with an MSE soniprep 150 (MSE Scientific Instruments Ltd., Sussex, UK) using four cycles of $3 \mathrm{~s}$ duration and at $70 \%$ power. After centrifugation at $20,000 g_{\text {av }}$ in the SS-34 rotor of a SORVAL RC5C laboratory centrifuge for $0.5 \mathrm{~h}$ at $4^{\circ} \mathrm{C}$, the sonicated DNA (sDNA) feedstock was portioned into sterile tubes and stored at $-20^{\circ} \mathrm{C}$. A size range of $0.4-10 \mathrm{kbp}$ for this preparation was determined by a combination of electrophoresis in horizontal $0.8 \%(\mathrm{w} / \mathrm{v})$ agarose gels, and size exclusion 
chromatography using an ÄKTAexplorerTM 100 air system (GE Healthcare Life Sciences, Amersham, United Kingdom). This involved applying small samples on a $60 \mathrm{~cm}$ bed of Sephacryl S-500 HR (contained in a Tricorn 10/600 column, GE Healthcare Life Sciences, Amersham, United Kingdom) that had been previously calibrated using DNA markers of known molecular size.

E. coli cells containing the plasmid pUG6 were grown in a $5 \mathrm{~L}$ batch fermenter on Luria Bertani (LB) broth (10 $\mathrm{g} \mathrm{L}^{-1}$ Tryptone, $5 \mathrm{~g} \mathrm{~L}^{-1}$ yeast extract, $\left.10 \mathrm{~g} \mathrm{~L}^{-1} \mathrm{NaCl}\right)$ containing $100 \mathrm{mg}$ $\mathrm{L}^{-1}$ ampicillin. The biomass was harvested after $\sim 20 \mathrm{~h}$ of cultivation (dry weight $\sim 10 \mathrm{~g} \mathrm{~L}^{-1}$ ) by centrifugation at $10,000 \mathrm{~g}_{\mathrm{av}}$ in the SLA 3000 rotor of a SORVAL RC5C centrifuge for $0.5 \mathrm{~h}$ at $4^{\circ} \mathrm{C}$. The cell paste was then washed by resuspension in $50 \mathrm{mM}$ Tris-HCl, $\mathrm{pH} 8$ buffer, before re-centrifuging as before, and storing at $-20^{\circ} \mathrm{C}$. Plasmid DNA (pDNA) was purified from thawed resuspended E. coli cell pastes using a QIAGEN Plasmid Maxi kit as described by the manufacturers.

\subsection{Static binding studies}

Supports $(0.1 \mathrm{~mL}$ drained matrix equilibrated in $50 \mathrm{mM}$ Tris- $\mathrm{HCl}, \mathrm{pH} 8)$ were contacted with solutions of BSA (16 mg in $5 \mathrm{~mL})$, sDNA (22.5 mg in $2.5 \mathrm{~mL}$ ) or pDNA (17.5 mg in $2.5 \mathrm{~mL}$ ) made up in $50 \mathrm{mM}$ Tris- $\mathrm{HCl}$, $\mathrm{pH} 8$ buffer, at room temperature $\left(\sim 22^{\circ} \mathrm{C}\right)$ on an orbital shaker (Infors, Basel, Switzerland). After binding (180 s for DNA, $1 \mathrm{~h}$ for BSA), supports were rapidly separated from suspension. The supernatants were then removed and analysed for residual protein or DNA contents (section 2.4).

\subsection{Expanded bed adsorption (EBA) experiments}

Given the small quantities of plasma-treated Q HyperZ expanded bed adsorbents generated in this work, all EBA runs were performed in a $1 \mathrm{~cm}$ diameter FastLine ${ }^{\mathrm{TM}} 10$ column (UpFront Chromatography A/S, Copenhagen, Denmark). The expanded bed column was connected to a FPLC system equipped with a P-1 peristaltic pump, flow-through UV-1 detector (254 nm) and FRAC-100 fraction collector (GE Healthcare, Uppsala, Sweden). Settled beds (4 - $4.5 \mathrm{~mL}$ giving heights, $\mathrm{H}_{0}$, of $5.1-5.7 \mathrm{~cm}$ ) of untreated and plasma treated (Et220-3 and pVAc170-3) Q HyperZ adsorbents were expanded with Milli Q water at a superficial flow rate of $350 \mathrm{~cm}$ $\mathrm{h}^{-1}$ and washed copiously, before equilibrating with $>50$ column volumes of $50 \mathrm{mM}$ Tris- $\mathrm{HCl}$, 
pH 8 supplemented with $0.1 \mathrm{M} \mathrm{NaCl}$ at the same fluid velocity, so that the conductivity of the exiting liquid reached that of the incoming buffer $(11 \mathrm{mS})$. Under these buffer and flow conditions, beds of all three adsorbent materials under test expanded approximately two-fold (i.e. $\mathrm{H} / \mathrm{H}_{0}=2$, where $\mathrm{H}$ is the height of the expanded bed). With the adsorbent beds now

5 primed for binding the various feedstocks $\left(1 \mathrm{~g} \mathrm{~L}^{-1} \mathrm{BSA}, 0.06 \mathrm{~g} \mathrm{~L}^{-1}\right.$ sDNA or $0.06 \mathrm{~g} \mathrm{~L}^{-1}$ pDNA) were applied at $350 \mathrm{~cm} \mathrm{~h}^{-1}$. In all cases loading was continued until the column outlet concentration reached at least $25 \%$ of the inlet value, and bed heights were periodically recorded. The BSA, sDNA and pDNA concentrations in the feedstocks and in collected fractions were determined at the end of each experiment by UV absorbance measurements as described earlier (section 2.4).

\section{Results and discussion}

\subsection{Selection of $\mathbf{Q}$ HyperZ for plasma modification}

The commercial anion exchange expanded bed adsorbent, Q HyperZ was selected for surface plasma modification for three main reasons, i.e. its unique 'gel-in-a-shell' architecture; availability in powder form with low water content (Table 1); and high binding capacity towards pDNA and sDNA $c f$. other beaded adsorbents.

Q HyperZ is a composite beaded material (Fig. 1) of high mechanical strength comprising a porous rigid skeleton of yttrium-stabilized zirconium oxide, which is completely filled and coated with a soft flexible functionalized hydrogel - synthesized by polymerizing the functional monomer, methacryloylaminopropyl trimethylammonium, together with the bifunctional cross-linking monomer, $\mathrm{N}, \mathrm{N}^{\prime}$-methylene bisacrylamide [56, 59]. During manufacture, the monomers and co-monomers are dissolved in an appropriate solvent and introduced into the bead in liquid form. Polymerization is then initiated to produce rigid beads, whose pores are filled with a cross-linked functionalised poly(acrylamide) gel. The volume of monomer solution is calculated so that in addition to completely filling the pores, the exterior surface is covered with a thin layer of gel (E. Boschetti, personal communication). Using confocal microscopy we have observed that this layer is of variable depth (data not shown). The thickness on most beads lies between 1 and $2 \mu \mathrm{m}$, but regions with much thinner coverage or no apparent cover, i.e. bare patches of shell, were also observed. 
Q HyperZ comes as a white powder with very low water content $(<5 \% \mathrm{w} / \mathrm{w} ; 1 \%$ for lot VC 220801). Thus we argued Q HyperZ might be able to withstand effects of dehydration in the low pressure atmosphere of the plasma reactor and potential abrasion during tumbling, much better than other beaded chromatography media, i.e. cross-linked polymeric matrices with high water contents.

Compared to other expanded bed matrices, Q HyperZ (and its packed bed equivalent Q HyperD) exhibits relatively high binding capacities towards pDNA and sDNA [18, 34]. Plasmids are as large as or larger than the pores of most beaded chromatography materials and thus any binding that occurs is strictly limited to the exterior surface $[16,18,60]$. Two architectural features of Hyper media are likely to be responsible for elevated pDNA and sDNA binding [18]. First, unlike most porous media the entire exterior surface of Hyper adsorbents is available for adsorption, and second, the thin layer of functionalised gel covering the surface (see Fig. 1) is highly folded [2].

15

\subsection{Strategies applied for plasma treatment}

Two strategies were employed to provide adsorbents devoid of (or depleted in) anion exchange functions at the exterior surface (Fig. 1), i.e.: plasma was used to either: (i) 'shave' away only those cationic ligands located at or close to the exterior surface (surface etching and oxidation) and replace them with polar oxygen containing ones, e.g. hydroxyls, carbonyls, carboxyls [38-45, 61, 62], or (ii) bury the surface exposed ligands of the native Q HyperZ adsorbent beneath a thin polymer blanket layer via plasma polymerization. The argon plasma creates radicals in the substrate's surface able to react with vinyl or acrylic monomers or radicals created in the plasma. Some etching will occur here also, but to a lesser extent given the reduced power employed. The plasma treatments explored in this work are presented in Table 2. Two of the monomers (Fig. 2) - vinyl acetate and vinyl pyrrolidone - were chosen for the antifouling characteristics that the resulting polymers - poly(vinyl acetate) and especially poly(vinyl pyrrolidone) - impart to surfaces [47-52, 63, 64], and the third (safrole) was used because previous work had shown this hydrophobic polycyclic compound polymerized very efficiently from gas plasma [65]. The power and treatment times employed were selected based on previous experience with plasma modification of other substrates, and some preliminary screening tests. 


\subsection{Elemental analysis of adsorbent surfaces using XPS}

We employed XPS to analyse the elemental composition of the first $10 \pm 1 \mathrm{~nm}$ depth of the exterior surfaces of Q HyperZ before and after exposure to various plasma treatments.

5 Examination of the XPS data following treatment of $5 \mathrm{~g}$ batches of Q Hyper Z (Table 2) confirms that all plasma modifications applied changed the elemental composition of $\mathrm{Q}$ HyperZ's surface. The various modified adsorbents are identified in abbreviated form by the treatments they received. Thus, an adsorbent that had been air plasma etched at $220 \mathrm{~V}$ for $2 \mathrm{~h}$ is identified by 'Et220-2', whereas one plasma polymerized with poly(vinyl acetate) at 170V for $3 \mathrm{~h}$ is denoted by 'pVAc170-3', etc.

The detection of $\mathrm{Zr}$ and $\mathrm{Y}$ at the surfaces of unmodified Q HyperZ is consistent with the confocal microscopic detection of thin surface gel and bare patches of exposed yttrium stabilised zirconia shell mentioned earlier (section 3.1). The reduction in atomic percent values (at. \%) of carbon and nitrogen to undetectable levels and parallel rises in at. \% levels of oxygen, zirconium, and yttrium, following air plasma etching (see Et220-2 and Et220-3 cf. untreated Q HyperZ), are entirely consistent with: (i) the removal of pendant trimethyl ammonium functional groups (or molecular layers of the Q-functionalised gel itself) from Q HyperZ; (ii) consequent increased exposure of the underlying shell; and (iii) surface oxidation, i.e. introduction of hydroxyl and carbonyl functions [38-45, 61, 62]. An increase in treatment time from 2 to $3 \mathrm{~h}$ exerted little impact on the elemental composition of the surface.

Following deposition of the plasma polymer coating on Q HyperZ the at. \% values for carbon increased, while those for zirconium and yttrium dropped. These changes were noted in all cases (regardless of monomer, power, time employed) providing strong evidence that polymerization coating had occurred at the adsorbent exterior. For plasma polymerization reactions with vinyl acetate, increasing the treatment time from 2 to $3 \mathrm{~h}$ was accompanied by an increase in at. $\% \mathrm{C}$, and significant reductions in at. $\% \mathrm{~N}, \mathrm{Zr}$ and $\mathrm{Y}$, implying that the polymer layer deposited on pVAc170-3 was deeper than that on pVAc170-2.

XPS analysis implies that plasma polymerization of vinyl acetate onto Q HyperZ under plasma was less efficient than with safrole or vinyl pyrrolidone. For example, treatment of Q 
HyperZ with a 'vinyl acetate - $170 \mathrm{~V}$ - 3h' plasma yielded significantly higher at. \% N, Zr and Y contents $c f$. Q HyperZ that had been exposed to a 'safrole $-130 \mathrm{~V}-0.5 \mathrm{~h}$ ' plasma treatment.

In contrast to other plasma treatments, i.e. air etching, or coating with poly(safrole) or poly(vinyl acetate), the at. \% $\mathrm{N}$ determined by XPS doubled following plasma modification with poly(vinyl pyrrolidone), i.e. from $5.1 \%$ to $10.0 \%$ for $\mathrm{pVP} 100-1$ and $11.6 \%$ for $\mathrm{pVP} 140$ 1. The elevated at. $\% \mathrm{~N}$ contents of these two materials reflect the higher nitrogen content of the vinyl pyrrolidone monomer (Fig. 2) $c f$. that of the substrate Q HyperZ, and provides firm evidence that surface modification with poly(vinyl pyrrolidone) had been occurred. Increasing the voltage during plasma deposition of poly(vinyl pyrrolidone), from 100 to $140 \mathrm{~V}$, was accompanied by very substantial drops in atomic percentages of $\mathrm{Zr}$ and $\mathrm{Y}$ at the adsorbent exterior, commensurate with a thicker coating due to a higher deposition rate.

Though significant drops in $\mathrm{Zr}$ and $\mathrm{Y}$ were detected for all polymer-coated Q HyperZ samples, their complete eradication from XPS analyses was not observed. This implies that the applied coatings: (i) were substantially less than $10 \mathrm{~nm}$ thick; and/or (ii) may not cover the entire outer support surface, leaving bare or thinly covered patches of yttrium-stabilised zirconia shell.

\subsection{Selectivity of 'surface versus core' modification of various plasma treatments}

The effects of the various plasma treatments on the selectivity of 'surface' over 'core' modification of Q HyperZ was evaluated in simple batch binding tests, conducted with sDNA $(0.4-10 \mathrm{kbp})$ or pDNA as probes for loss in surface binding and BSA to gauge for reduction in core binding. Q HyperZ is a composite chromatographic support that uses hyper-diffusion (also known as surface or solid diffusion) to enhance mass transfer of proteins and other small molecules, i.e. adsorbed proteins move within the functionalised gel [2]. However, it is clear that, in common with other more conventional porous beaded chromatography supports, the binding of pDNA and large sDNA fragments to Hyper media (e.g. Q HyperZ and Q HyperD) is confined to their exterior surface [16-18, 34, 60, 66-68] and occurs within a much shorter timescale than protein sorption $[31,34,67,68]$. Figure 4a shows loss in surface DNA binding of the plasma treated supports listed in Table 2 plotted as a function of their loss in core BSA binding, and Figure $4 \mathrm{~b}$ summarises the relative success of the different plasma treatments in 
terms of a selectivity index, calculated simply by dividing the \% retained core BSA binding by the $\%$ retained surface DNA binding - the higher the number the better the support.

Surface etching and oxidation produced the greatest reduction in surface sDNA and pDNA binding (Fig. 4a) and also the highest selectivity index, i.e. 2.0 for Et220-3 (Fig. 4b). For example, Et220-3 possessed less than half of the sDNA and pDNA binding capacity of untreated Q HyperZ (Fig. 4a) whilst retaining a high level of core BSA binding (i.e. $>90 \%$ ).

XPS analysis of Et220-3 (Table 2) indicated that sufficient Q-functionalized polyacrylamide gel had been removed to expose the underlying zirconium oxide shell. The protein sorption characteristics of zirconium oxide are complex. Voute and co-workers [59] showed that bare zirconium oxide is unable to bind cytochrome $c(\mathrm{pI}=10.2)$ at any $\mathrm{pH}$ between 4.5 and 8.6, indicating that its surface is cationic, and that BSA (pI = 5.1) adsorbed non-selectively on zirconia via non-ionic interactions. Further, the sorption behaviour of naked zirconia is highly dependent on the buffer system employed. For example, following prior incubation with a

15 strong Lewis base (e.g. $0.5 \mathrm{M}$ phosphate) the zirconia surface was able to acquire anionic character, because Lewis acid sites on the surface bound Lewis bases from solution to generate a negative charged exterior [59, 69]. Despite all of the above the contributions of exposed zirconia shell to the BSA binding properties of Et220-3 are likely to be negligible. This is because an extremely low percentage of shell surface is likely to be available for 20 binding; the surface area of the empty porous yttrium-stabilised zirconia shell used in the construction of Q HyperZ is just $1 \mathrm{~m}^{2} / \mathrm{g}$.

A relatively high selectivity index (1.49) was also observed for the poly(safrole) treated Q HyperZ. However, unlike all other plasma treated supports this material was deemed unsuitable for EBA given its propensity to agglomerate strongly in aqueous solutions - an observation consistent with safrole's polycyclic ring structure (see Fig. 2). The poly(vinyl acetate) coated adsorbents displayed comparatively modest selectivity indices (1.13 - 1.37, Fig. 4b); but the best reduction in sDNA binding capacity exhibited by a plasma polymer modified Q HyperZ was shown by pVAc170-3 (Fig. 4a). The BSA and sDNA binding 30 characteristics of poly(vinyl pyrrolidone) modified adsorbents were quite different to those of other plasma treated Q HyperZ supports. These polymer coated materials were characterised by selectivity indices less than unity (Fig 4b). Poly(vinyl pyrrolidone) is widely recognized as 
a potentially important surface modification agent for biomedical and bioprocessing applications, given its excellent biocompatibility with living tissues and extremely low cytotoxicity [70], and that it prevents cell adhesion, inhibits binding of platelets [52] and plasma proteins [51, 52, 63], increases surface wettability and reduces adsorptive fouling [4850]. Numerous studies conducted with model proteins, including BSA, confirm that modification of a given support material with poly(vinyl pyrrolidone) significantly reduces protein adsorption. In contrast, reports on nucleic acid binding to poly(vinyl pyrrolidone) or poly(vinyl acetate) modified materials could not be found. The inverted 'surface/core' selectivity behaviour noted for poly(vinyl pyrrolidone) coated Q HyperZ cf. all other plasma modified adsorbents in this study (i.e. greater reduction to core BSA than to surface sDNA binding) provides evidence that nucleic acid adsorption is less strongly affected by poly(vinyl pyrrolidone).

For surface etched Q HyperZ the most obvious cause of loss in core BSA binding is removal 15 of ion exchange ligands from the outermost surface of the matrix. In order to establish how far into the support plasma etching had extended, we made careful measurements of the ionic capacity of Q HyperZ before and after the air plasma etching treatment. The original chloride exchange capacity, of $131.4 \mathrm{mmol} \mathrm{mL}^{-1}$ (Table 1) for Q HyperZ, fell following $3 \mathrm{~h}$ exposure to air plasma to $118.3 \mathrm{mmol} \mathrm{mL}^{-1}$ (Table 3 ). This $10.0 \%$ drop in ionic capacity almost exactly mirrored the loss in core BSA binding (9.3\%, Fig. 4a). Assuming an average bead diameter of $70 \mu \mathrm{m}$ (Table 1), and two further oversimplified assumptions, i.e. uniform distribution of ligand throughout the support, and an absolute distinction between etched and non-etched regions, a $10 \%$ loss in $\mathrm{Cl}^{-}$exchange capacity (or BSA binding) translates to a mean 'effective' modification depth within the hydrated particle of $1.2 \mu \mathrm{m}$. In truth, the situation is a good deal more complex than this, given that: (i) the method of manufacture of Q HyperZ results in sorbent beads encased in a thin layer of functionalised gel (section 3.1); thus the distribution of ligand within a Q HyperZ bead is not uniform - it is slightly more concentrated at the bead surface; and (ii) formation of a clear-cut boundary, separating modified and unmodified regions, is unlikely.

The rigid porous zirconia skeleton of Q HyperZ prevents swelling of the 3-dimensional polymerized cationic hydrogel locked inside [2]. The thin surface gel-layer however, is not 
subject to the same physical constraints, and is therefore able to swell significantly (from the initial polymerized or dry state) on immersion in aqueous solvents. Plasma etching was performed when the adsorbent was in the form of a dry powder, thus the actual depth of penetration achieved during the plasma treatment is likely to be much less than the $1.2 \mu \mathrm{m}$ estimate for a hydrated $70 \mu \mathrm{m}$ Q HyperZ particle. Under these conditions, the gel-layer coating the adsorbent's exterior will be in a dehydrated and therefore collapsed state, i.e. it will be very much thinner. In water the swollen state of the cationic hydrogel used to fill $\mathrm{Q}$ HyperZ is $>14$ times that of the original polymerized constrained state ${ }^{2}$; this is largely due to repulsion between like charges along the polymer backbone [2]. The depth of the dry collapsed gel-layer will be much smaller again than the original constrained state. Thus, a more realistic estimate of the air plasma etching penetration depth into Q HyperZ is of the order of $20 \mathrm{~nm}$ or more, and is certainly greater than the maximum XPS analysis depth of 10 nm.

The significant losses in core BSA binding for polymer coated supports are more complex to explain. Here again, reductions in ionic capacity were observed, but were too small to fully account for the loss in core BSA binding determined (e.g. for pVAc170-3 the reduction in $\mathrm{Cl}^{-}$ exchange capacity and BSA binding were 4.4\% (Table 3) and $17 \%$ (Fig. 4a) respectively. The 'additional loss' in protein binding as a consequence of polymer coating at and beneath the immediate exterior surface, i.e. in a sub-surface region (ca. $0.5 \mu \mathrm{m}$ for pVAc170-3; Table 3), can be assigned to steric and mass transfer related effects.

Just two of the original seven plasma treatments in Table 2 were selected for further study, i.e. 'surface etching at $220 \mathrm{~V}$ for $3 \mathrm{~h}$ ' and 'surface coating with poly(vinyl acetate) at $170 \mathrm{~V}$ for 3 h'. Multiple batches of identically prepared Et220-3 and pVAc70-3 were pooled to provide sufficient of each matrix for SEM, light microscopy/particle sizing, ionic capacity determinations and three parallel expanded bed runs (using $4-4.5 \mathrm{~mL}$ settled beds in Fastline 10 contactors) with BSA, sDNA and pDNA containing feedstocks. Table 3 illustrates the impact of treated batch size on surface XPS and core ionic capacities of Q HyperZ following

\footnotetext{
${ }^{2}$ Prior and during polymerization of the cationic gel filling the HyperZ skeleton electrostatic repulsion between the positively charged monomers is heavily suppressed using appropriate salts and solvents. After polymerization, and when charge shielding is lifted, the hydrogel, if unconstrained, expands dramatically as like charges repel one another strongly [2].
} 
plasma etching and plasma polymerization coating with poly(vinyl acetate). An approximate doubling in batch size from 5 to $10.5 \mathrm{~g}$ exerted relatively little impact on the elemental compositions of the first $c a .10 \mathrm{~nm}$ of Et220-3 and pVAc170-3 supports, but essentially halved the loss in ionic capacity (from 10 to $4.2 \%$ for Et $220-3$ and from 4.4 to $2.0 \%$ for pVAc170-30. As the support mass (and therefore exterior surface) treated per litre of plasma is doubled (i.e. from 25 to $52.5 \mathrm{~g} \mathrm{~L}^{-1}$ ) the effective numbers of active species in the plasma bombarding a given patch of support surface are effectively halved, and thus the extent and 'effective' depth of modification is significantly reduced (i.e. from 1.2 to $0.5 \mu \mathrm{m}$ for Et220-3 and from 0.5 to $0.2 \mu \mathrm{m}$ for $\mathrm{pVAc} 170-3)$.

\subsection{Impact of plasma treatment on the appearance and size of Q HyperZ}

Scanning electron microscopy at 1000- and 10,000- fold magnifications was unable to reveal discernible differences (down to the ca. $0.2 \mu \mathrm{m}$ level) in size or surface morphology of Et2203, pVAc170-3 and untreated Q HyperZ beads following plasma modification at the $10.5 \mathrm{~g}$ scale (Fig. 5). No changes in the appearance of Q HyperZ before and after plasma treatment could be seen under light microscopy - the particle size distributions (Fig. 6a-c) and mean particle diameters (73.3, 72.2 and 73.2 $\mu \mathrm{m}$ for untreated Q HyperZ, Et220-3 and pVAc170-3 respectively) were strikingly similar - and nor was there any evidence for plasma induced damage, such as e.g. increased generation of fines, presence of fragmented supports and/or changes in bead shape.

\section{6 Expanded bed adsorption (EBA) studies}

XPS surface analysis (Tables $2 \& 3$ ) confirmed that all plasma treatments inflicted significant changes to the surface of Q HyperZ, and that increasing the batch size reduced ligand loss in predictable fashion (Table 3). The extent to which air plasma etching and plasma polymer coating (conducted using $52.5 \mathrm{~g}$ of Q HyperZ per L of plasma) affected the ability of the resulting adsorbents to bind pDNA, sDNA and BSA in expanded beds is presented in Fig.7. At the operating flow rate of $350 \mathrm{~cm} \mathrm{~h}^{-1}$ (initial expansion $\mathrm{H} / \mathrm{H}_{0}=2$; initial voidage, $\varepsilon_{\mathrm{i}}=0.7$ ) in a $50 \mathrm{mM}$ Tris- $\mathrm{HCl} \mathrm{pH} 8$ buffer containing $0.1 \mathrm{M} \mathrm{NaCl}$ the dynamic binding capacities at $10 \%$ breakthrough $\left(\mathrm{DBC}_{10 \%}\right)$ of untreated Q HyperZ for pDNA, sDNA and BSA were 1.5 (Fig. 7a), 6.9 (Fig. 7b) and 33.5 (Fig. 7c) $\mathrm{mg} \mathrm{mL}^{-1}$ respectively. Following poly(vinyl acetate) deposition (pVAc170-3) the pDNA $\mathrm{DBC}_{10 \%}$ dropped by nearly $30 \%$ to $1.1 \mathrm{mg} \mathrm{mL}^{-1}$ (Fig. $7 \mathrm{a}$ ) 
and an even greater reduction in dynamic pDNA binding of 50\% $\left(0.75 \mathrm{mg} \mathrm{mL}^{-1}\right)$ was observed for the air plasma etched 'Et220-3' Q HyperZ (Fig. 7a). Even greater reductions in $\mathrm{DBC}_{10 \%}$ following plasma treatment were found when sDNA was employed as a probe for surface binding. The air plasma etching treatment wiped out nearly $85 \%$ of the DBC for sDNA (a drop from 7 to $<1.3 \mathrm{mg} \mathrm{mL}^{-1}$, Fig. $7 \mathrm{~b}$ ), and although pVAc coating proved less effective, it nevertheless reduced dynamic sDNA binding by nearly 65\% (Fig. 7b). The significant reductions in $\mathrm{DBC}_{10 \%}$ of 'surface' binding probes, pDNA and sDNA, observed following both plasma treatment of Q HyperZ (Figs 7a and b respectively) are in striking contrast to the almost complete absence of a loss in both 'core' BSA binding (Fig. 7c) and ion exchange capacity (Table 3 ) for the same adsorbent materials (i.e. $\mathrm{DBC}_{10 \%}$ values of 33.5 , $32.8 \& 34.8 \mathrm{mg} \mathrm{mL}^{-1}$, and $\mathrm{Cl}^{-}$exchange capacities of $131.4,125.9 \& 128.8 \mathrm{mmol} \mathrm{L}^{-1}-$ for untreated, Et220-3 and pVAc170-3 supports respectively).

A common feature during the application of sDNA containing liquors onto expanded beds of anion exchange adsorbents is, to varying degrees depending on the particular support and prevailing ionic strength, the progressive contraction of the bed caused by sDNA molecules pulling or flocculating neighbouring adsorbent particles together resulting in aggregated and physically cross-linked fluidised beds $[18,25,31,34]$. In these experiments the suspending buffer $(50 \mathrm{mM}$ Tris/HCl $\mathrm{pH} 7.5)$ was supplemented with $0.1 \mathrm{M} \mathrm{NaCl}$; the reason being that previous work with expanded beds of Q HyperZ and sDNA feedstocks showed that this action eliminated flow channelling within the expanded bed, without influencing bed contraction behaviour. Scrutiny of bed contraction profiles during the application of BSA (Fig. 7c), pDNA (Fig. 7a) and sDNA (Fig. 7b) on two-fold expanded beds of unmodified and plasma treated Q HyperZ confirmed that: (i) bed contraction only occurred when the feedstock contained sDNA; and (ii) severe bed contraction was only observed for the unmodified Q HyperZ. In this case, the bed progressively contracted reaching a minimum voidage $(\varepsilon=0.62$; $\mathrm{H} / \mathrm{H}_{0}<1.6$ ) after applying $5 \mathrm{mg} \mathrm{sDNA} / \mathrm{mL}$ support, before gradually re-expanding as further sDNA feedstock was supplied to the bed. Clearly, both plasma treatments were effective in reducing the extent of DNA induced bed contraction (Fig. 7b). Taken collectively, the bed contraction and dynamic binding data presented here supports the assertion that the low temperature low pressure plasma etching and coating methods we have applied can be used to effectively modify the surface of adsorbents without significantly compromising the binding 
properties of the core. It is reasonable to assume that the plasma treatments identified here as effective solutions for dealing with expanded bed adsorptive separations from problematic nucleic acid containing feedstocks, should also be applicable to EBA from other troublesome feedstocks, such as those containing whole or disrupted cells, as well as to packed bed chromatographic separation of nanoplex species from smaller chemically similar contaminants.

\section{Conclusions}

Low temperature plasma discharge treatment is an effective means of conducting nano-scale surface modifications to beaded chromatography adsorbents. Ligands can be shaved off the surface of adsorbents via plasma etching and oxidation, or coated with a nano-thin polymer layer by plasma polymerization. The plasma treatments are gentle and physical damage to the adsorbents was not observed. Plasma modification of Q HyperZ supports resulted in adsorbents with (i) substantially reduced surface charge, (ii) much lower binding capacity towards large DNA molecules and (iii) reduced sensitivity to sDNA induced bed contraction, and (iv) without compromising mass transfer and binding of BSA to the interior functionalised core of the supports. In general, the results found in this work suggest that removing surface ligands by air plasma etching was more successful than covering them via plasma polymerization. However, as only three monomers were applied in this study, it is entirely possible that the use of others could make plasma polymerization an equally attractive or better option than etching.

The procedures described in this work have been applied to commercially available adsorbents. The generation of large quantities of bi-layered supports from such starting materials using plasma technology should be relatively straightforward. No complicated redesign or engineering of the manufacturing process is required, and plasma treatment for the similar applications, e.g. preparation of dispersible polyolefin powders (diameter $20-120$ $\mu \mathrm{m}$ ) by oxygen plasma, is already conducted at large scale using reactors of $\sim 120 \mathrm{~L}$ volume [71,72]. Plasma modification could thus be an 'add on' treatment to already established packed bed and EBA chromatography adsorbent manufacturing processes. 
Careful optimization of plasma treatment parameters has not been the focus of this work, but is clearly a prerequisite prior to establishing robust methods for large scale preparation of bilayered chromatographic supports with non-adsorptive surfaces. Finally, the extension of low temperature low pressure plasma treatments disclosed here for Q HyperZ, to other beaded chromatographic support materials, and selection of alternative coatings tailored to specific functions (i.e. other neutral hydrophilic, functionalised or even smart polymers with switchable behaviour), should be done in order to assess whether plasma methods have a role to play in the future provision of multi-functional chromatography materials for the bioprocess industries.

\section{Acknowledgements}

The authors thank Lene Hubert (Danish Polymer Research Centre, Risø National Laboratory, Denmark) for expert technical assistance with XPS. A.A gratefully acknowledges the 15 financial support afforded by a $\mathrm{PhD}$ scholarship from the Iranian Ministry of Science, Research and Technology, and funding from the Biotechnology and Biological Sciences Research Council/Bioprocessing Research Industry Club (BBSRC/BRIC) programme (Grant $\mathrm{BB} / \mathrm{F} 004982 / 1$ ) is greatly appreciated and recognized.

\section{References}

[1] J.-C. Janson, P. Hedman, Adv. Biochem. Eng. 25 (1982) 43.

[2] E. Boschetti, J. Coffmann, in: G. Subramanian, Bioseparation and Bioprocessing, Vol. 1, Wiley-VCH Verlag GmbH, Weinheim, Germany, 1998, p.157.

[3] T.M. Przybycien, N.S. Pujar, L.M. Steele, Curr. Opin. Biotechnol. 15 (2004) 469.

25 [4] G. Jagschies, BioPharm Inter. 21 (Oct 2008) 72.

[5] U. Gottschalk, BioPharm Inter., 18, (June 2005) 42.

[6] L. Giovannoni, M. Ventani, U. Gottschalk, BioPharm Inter. 21(Dec 2008) 48.

[7] P.-E. Gustavsson, R. Lemmens, T. Nyhammar, P. Busson, P.-O. Larsson, J. Chromatogr. A 1038 (2004) 131.

30 [8] C. Kepka, R. Lemmens, J. Vasi, T. Nyhammar, P.-E. Gustavsson, J. Chromatogr. A 1057 (2004) 115.

[9] M.B. Dainiak, I.Y. Galaev, B. Mattiasson, J. Chromatogr. A 942 (2002) 123. 
[10] M.E. Viloria-Cols, R. Hatti-Kaul, B. Mattiasson, J. Chromatogr. A 1043 (2004) 195.

[11] M.B. Dainiak, I.Y. Galaev, B. Mattiasson, Biotechnol. Prog. 18 (2002) 815.

[12] M. Jahanshahi, L. Partida-Martinez, S. Hajizadeh, J. Chromatogr. A 1203 (2008) 13.

[13] A. Lyddiatt, D.A. O’Sullivan, Curr. Opin. Biotechnol. 9 (1998) 177.

5 [14] G.F. Walker, E. Wagner, in: D.T. Curiel, J.T. Douglas (Eds.) Cancer Gene Therapy, Humana Press, Totowa, New Jersey, USA, 2005, p. 367.

[15] A. Agarwal, R.C. Unfer, S.K. Mallapragada, Biomaterials 29 (2007) 607.

[16] D.M.F. Prazeres, G.N.M. Ferreira, G.A. Monteiro, C.L. Cooney, J.M.S. Cabral, Trends Biotechnol. 17 (1999) 169.

10 [17] G.N.M. Ferreira, G.A. Monteiro, D.M.F. Prazeres, J.M.S. Cabral, Trends Biotechnol. 18 (2000) 380-388.

[18] I. Theodossiou, M. Søndergaard, O.R.T. Thomas, Bioseparation, 10 (2001) 31.

[19] D.M.F. Prazeres, G.N.M. Ferreira, Chem. Eng. Proc. 43 (2004) 615.

[20] E. Theodosiou, O.R.T. Thomas, J. Chem. Technol. Biotechnol.83 (2008) 192.

15 [21] S.S. Freitas, S. Canaro, J.A.L. Santos, D.M.F. Prazeres, Biotechnol. J. 4 (2009) 265.

[22] H.A. Chase, Trends Biotechnol. 12 (1994) 296.

[23] R. Hjorth, Trends Biotechnol. 15 (1997) 230.

[24] J. Thömmes, in: T. Scheper (Ed.), Advances in Biochemical Engineering / Biotechnology, Vol. 58, Springer, Berlin, Germany, 1997, p. 185.

20 [25] I. Theodossiou, O.R.T. Thomas, J. Chromatogr. A 971 (2002) 73.

[26] A. Sonnenfeld, J. Thömmes, in: A.A. Shukla, M.R. Etzel, S. Gadam (Eds.), Process scale bioseparations for the biopharmaceutical industry, CRC Press, Boca Raton, Florida, USA, 2007, p. 59.

[27] N. Ameskamp, C. Priesner, J. Lehmann, D. Lütkemeyer, Bioseparation 8 (1999) 169.

[28] F.B. Anspach, D. Curbelo, R. Hartmann, G. Garke, W.D. Deckwer, J. Chromator. A 865 (1999) 129.

[29] J. Feuser, J. Walter, M.R. Kula, J. Thömmes, Bioseparation, 8 (1999) 99.

[30] J. Feuser, M. Halfar, D. Lutkemeyer, N. Ameskamp, M.R. Kula, J. Thömmes, Process Biochem. 34 (1999) 159.

30 [31] I. Theodossiou, M.A. Olander, M. Søndergaard, O.R.T. Thomas, Biotechnol. Letts 22 (2000) 1929.

[32] D.Q. Lin, J. Thömmes, M.R. Kula, J. Hubbuch, Biotechnol. Bioeng. 87 (2004) 337. 
[33] J.J. Hubbuch, P.J. Brixius, D.Q. Lin, I. Mollerup M.R. Kula, Biotechnol. Bioeng. 94 (2006) 543.

[34] A. Arpanaei, Ph.D. Thesis, Technical University of Denmark, Lyngby, 2008

[35] K. Kaczmarski, J.C. Bellot, Biotechnol. Prog. 20 (2004) 786.

5 [36] J. Yun, D.Q. Lin, S.J. Yao, J. Chromatogr. A 1095 (2005) 16.

[37] E.R. Fisher, Plasma Sources Sci. Technol. 11 (2002) 175.

[38] D.C. Schram, Th.H.J. Bisschops, G.M.W. Kroesen, F.J. de Hoog, Plasma Phys. Controlled Fusion 29 (1987) 1353.

[39] J.R. Hollahan, G.L. Carlson, J. Appl. Polymer Sci. 14 (1970) 2499.

10 [40] Y. Yamamoto, S. Oka, K. Hayashi, Bull. Chem. Soc. Japan, 57 (1984), 3450.

[41] H.V. Boenig, Fundamentals of plasma chemistry and technology, Technomic Pub., Lancaster. 1998.

[42] N. Inagaki, S. Tasaka, Y. Horikawa, Polym. Bull. 26 (1991) 283.

[43] M. Ulbricht, G. Belfort, J. Appl. Polymer Sci. 56 (1995) 325.

15 [44] P. Kingshott, H.J. Griesser, Curr. Opin. Solid State Mater. Sci. 4 (1999) 403.

[45] S.L. McArthur, K.M. McLean P. Kingshott, H.A.W. St John, R.C. Chatelier, H.J. Griesser, H.J., Colloids Surf., B 17 (2000) 37.

[46] P. Kingshott, H. Thissen, H.J. Griesser, Biomaterials 23 (2002), 2043.

[47] M.K. Ko, J.J. Pellegrino, R. Nassimbene, P. Marko, J. Membr. Sci. 76 (1993) 101.

20 [48] H. Chen, G. Belfort, J. Appl. Polym. Sci. 72 (1999) 1699.

[49] J. Pieracci, J.V. Crivello, G. Belfort, J. Membr. Sci. 156 (1999) 223.

[50] J. Pieracci, J.V. Crivello, G. Belfort, Chem. Mater. 12 (2000) 2123.

[51] J. Marchese, M. Ponce, N.A. Ochoa, P. Pradanos, L. Palacio, A. Hernandez, J. Membr. Sci. 211 (2003) 1.

25 [52] Z-M. Liu, Z-K. Xu, J-Q. Wang, J. Wu, J-J. Fu, Eur. Polym. J 40 (2004) 2077.

[53] S. Souverain, S. Rudaz, J.L. Veuthey, J. Chromatogr. B 801 (2004) 141.

[54] Y. Sudo, R. Miyagawa, Y. Takahata, J. Chromatogr. B 705 (1998) 55.

[55] J.M. Coulson, J.F. Richardson, J.R. Backhurst, J.H. Harker, Chemical Engineering, Vol. 2, Pergamon Press, Oxford, 1991

30 [56] N. Voute, E. Boschetti, Bioseparation 8 (1999) 115.

[57] U. Guldener, S. Heck, T. Fielder, J. Beinhauer, J.H. Hegemann, Nucleic Acids Res. 24 (1996) 2519. 
[58] A.I. Vogel, Vogel's Textbook of Quantitative Chemical Analysis, Bath Press, Avon, UK (1989).

[59] N. Voute, D. Bataille, P. Girot, E. Boschetti, Bioseparation 8 (1999) 121.

[60] A. Ljunglöf, P. Bervall, R. Bhikhabhai, R. Hjorth, J. Chromatogr. A 844 (1999) 129.

5 [61] J.Y. Lai, Y.Y. Lin, Y.L. Denq, S.S. Shyu, J.K. Chen, J. Adhes. Sci. Technol. 10 (1996) 231 .

[62] H.R. Kim, H.H. Park, S.H. Hyun, G.Y. Yeom, Thin Solid Films, 332(1998) 444.

[63] S. Robinson, P.A. Williams, Langmuir 18 (2002) 8743.

[64] T. Hoshi, T. Sawaguchi, T. Konno, M. Takai, K. Ishihara, Polymer 48 (2007) 1573.

10 [65] B. Winther-Jensen, K. West, US Patent Application US2007/0202612 (2007).

[66] M. Colpan, D. Riesner, J. Chromatogr. A 296 (1984) 339.

[67] G.N.M. Ferreira, J.M.S. Cabral, D.M.F. Prazeres, Biotechnol. Prog. 16 (2000) 416.

[68] C. Tarmann, A. Jungbauer, J. Sep. Sci. 31 (2008) 2605.

[69] C.J. Dunlap, P.W. Carr, J. Liq. Chromatogr. Related Technol. 19 (1996) 2059.

15 [70] G.M.R. Wetzels, L.H. Koole, Biomaterials 20 (1999) 1879.

[71] R.J. Babacz, US Patent US5234723 (1993).

[72] M.R. Wertheimer, H.R. Thomas, M.J. Perri, J.E. Klemberg-Sapieha, L. Martinu, Pure Appl. Chem. 68 (1996) 1047. 


\section{Figure captions}

Fig. 1. Strategies applied for plasma surface modification of Q HyperZ adsorbent beads. Here '+' represents the quaternary amine ligand distributed on the surface and throughout the adsorbent.

Fig. 2. Monomers employed for low temperature/low pressure plasma polymerization coating of Q HyperZ.

Fig. 3. Rotating low temperature low pressure reactor set-up for plasma etching and oxidation and plasma polymerization coating.

Fig. 4. (a) Reduction in surface DNA binding vs. reduction in core BSA binding and (b) the resulting 'surface vs. core' selectivity indices for the plasma treated Q HyperZ adsorbents listed in Table 2 (5 g scale). Key: sDNA (up-triangles); pDNA (down-triangles); plasma polymerized (black bars); and plasma etched (white bars) Q HyperZ. The BSA, sDNA and pDNA binding capacities of untreated Q HyperZ in $50 \mathrm{mM}$ Tris-HCl, $\mathrm{pH} 8$ were respectively 70.6, 4.4 and $3.1 \mathrm{mg}$ per $\mathrm{mL}$ adsorbent.

Fig. 5. SEM images of (a) untreated, (b) plasma etched 'Et220-3', and (c) plasma polymerized 'pVAc170-3' Q HyperZ adsorbents (Table 3, $10.5 \mathrm{~g}$ scale) at $1000 \times($ top) and 10,000 $\times$ (bottom) magnification. The white size bars represent 10 and $1 \mu \mathrm{m}$ for the low and high magnification fields respectively.

Fig. 6. Particle size distributions and light microscopy images (inserts) of (a) untreated, (b) plasma etched 'Et220-3', and (c) plasma polymerized 'pVAc170-3' Q HyperZ adsorbents (Table 3, $10.5 \mathrm{~g}$ scale). Mean particle sizes of 73.3, 72.2 and $73.2 \mu \mathrm{m}$ were determined for the untreated, Et220-3 and pVAc170-3 adsorbent preparations respectively.

Fig. 7. Breakthrough curves and bed contraction profiles during the binding of (a) pDNA, (b) sDNA and (c) BSA to expanded beds of untreated, plasma etched 'Et220-3', and plasma polymerized 'pVAc170-3' Q HyperZ adsorbents (Table 3, 10.5 g scale). Key: Untreated (filled grey symbols), 'Et220-3' (open symbols) and 'pVAc170-3' (filled black symbols) Q 
HyperZ adsorbents; pDNA $(\nabla, \nabla, \boldsymbol{\nabla})$; sDNA $(\triangle, \triangle, \mathbf{\Delta})$; BSA $(\bigcirc, \bigcirc, 0)$; and bed voidage, $\varepsilon$ ( $\square, \square, \square)$. Bed voidage was calculated employing assuming a value of 0.4 for the settled bed $[55]$. 
Q - functionalized hydrogel

Methacryloylaminopropyl

trimethyl ammonium / N,N'-

methylene bisacrylamide

copolymer
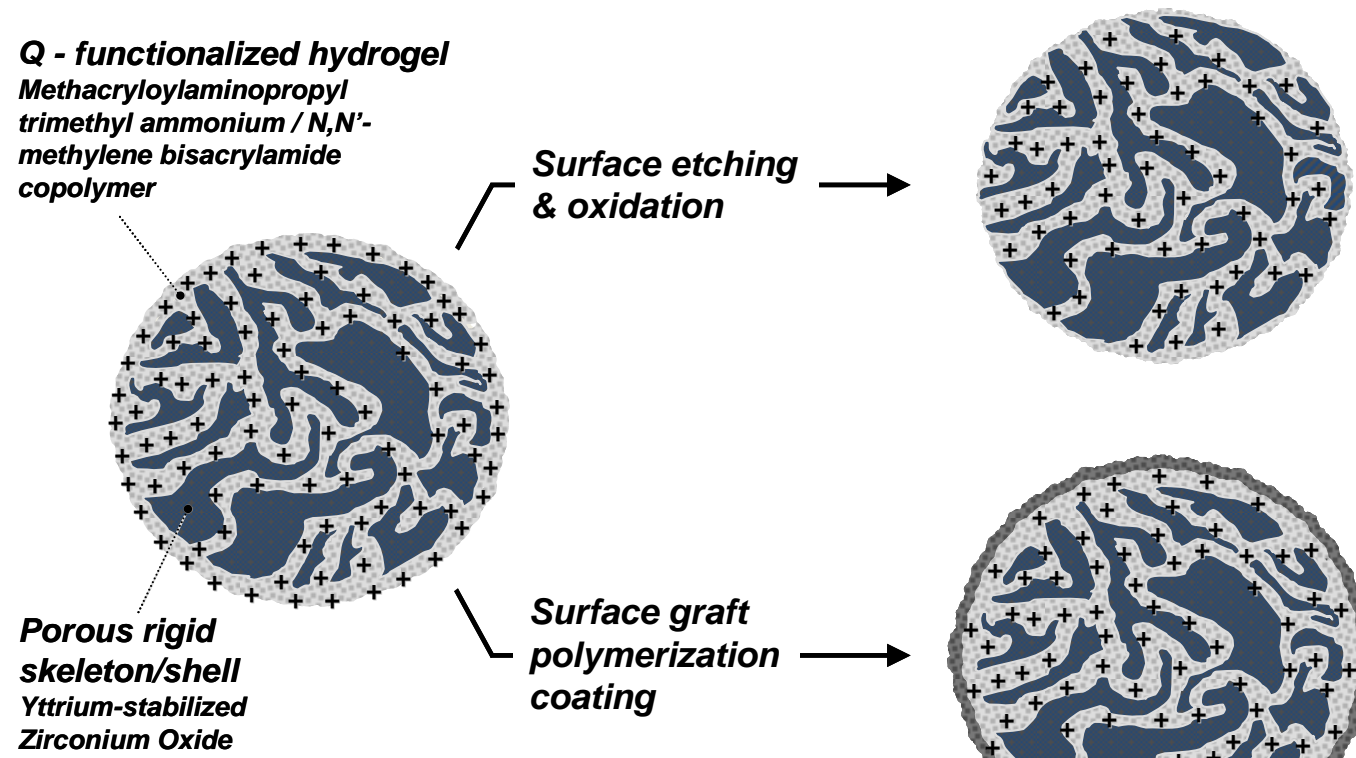

Zirconium Oxide

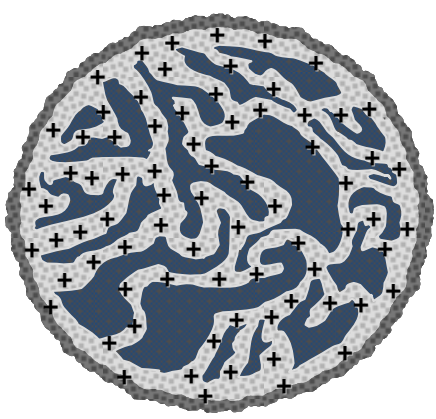

Figure 1 


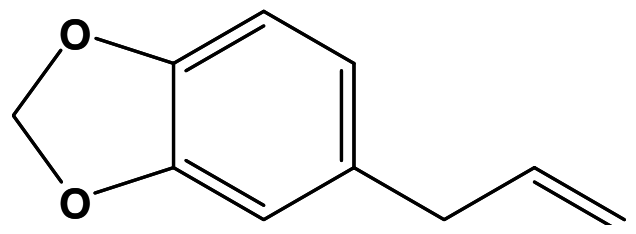

5-allylbenzo[d][1,3]dioxole

(safrole)<smiles>C=COC(C)=O</smiles>

methyl-3-butenoate

(vinyl acetate)<smiles>C=CN1CCCC1=O</smiles>

1-vinylpyrrolidin-2-one (vinyl pyrrolidone)

Figure 2 


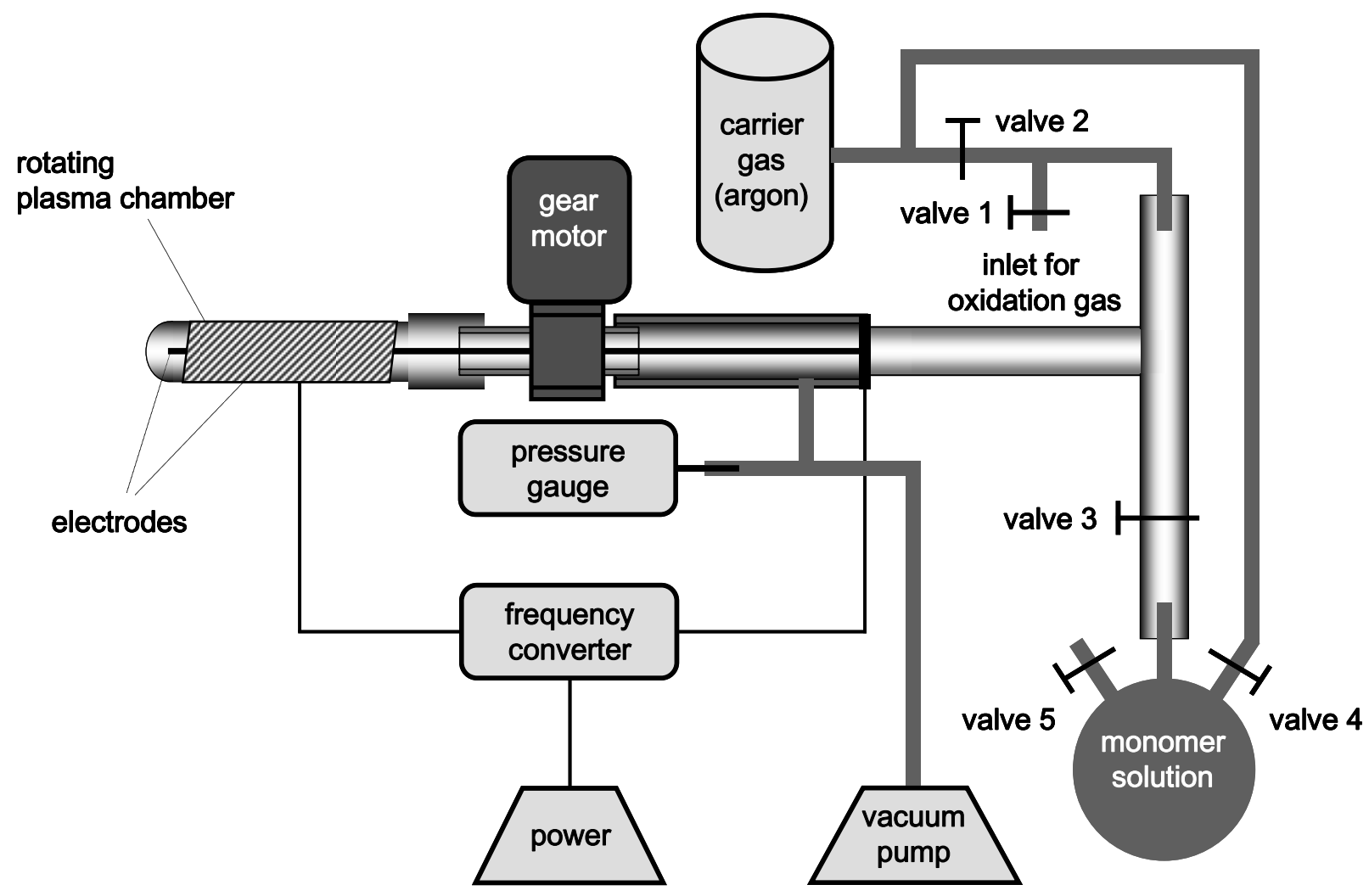

Figure 3 

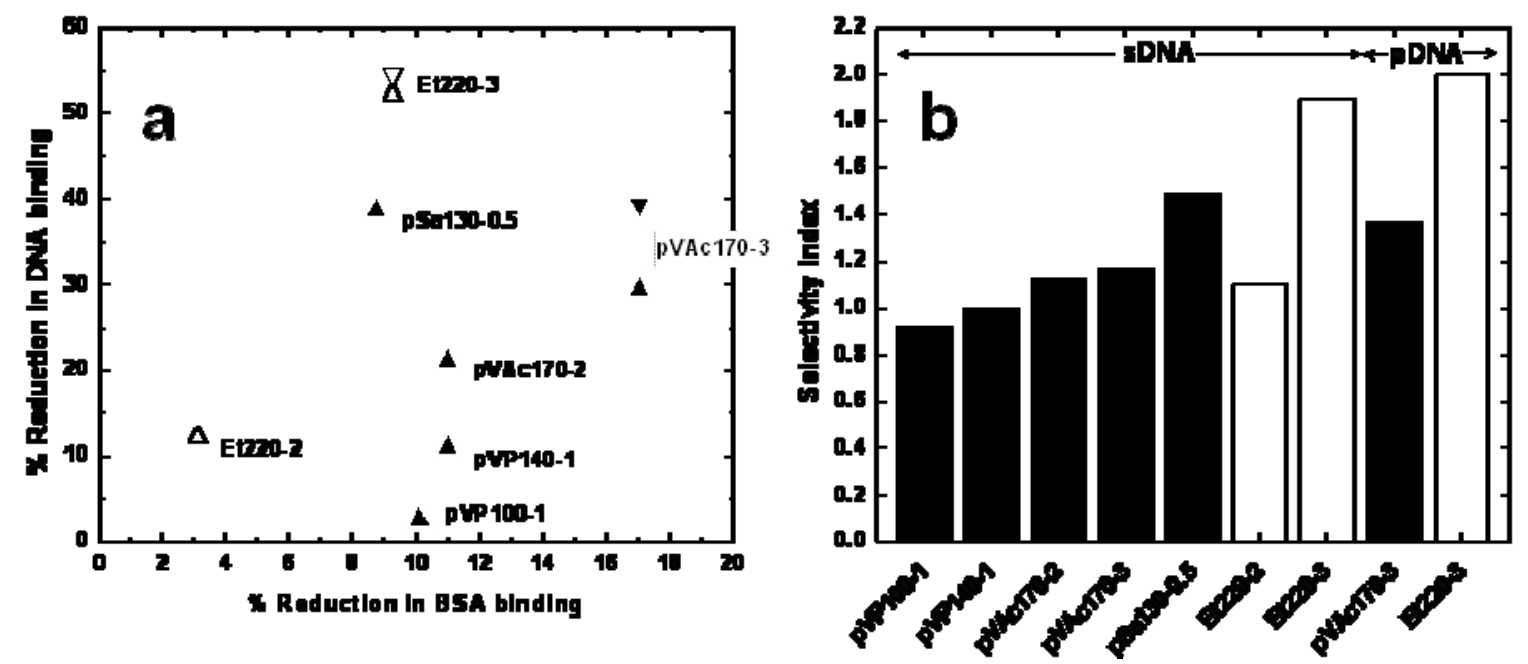

Figure 4 


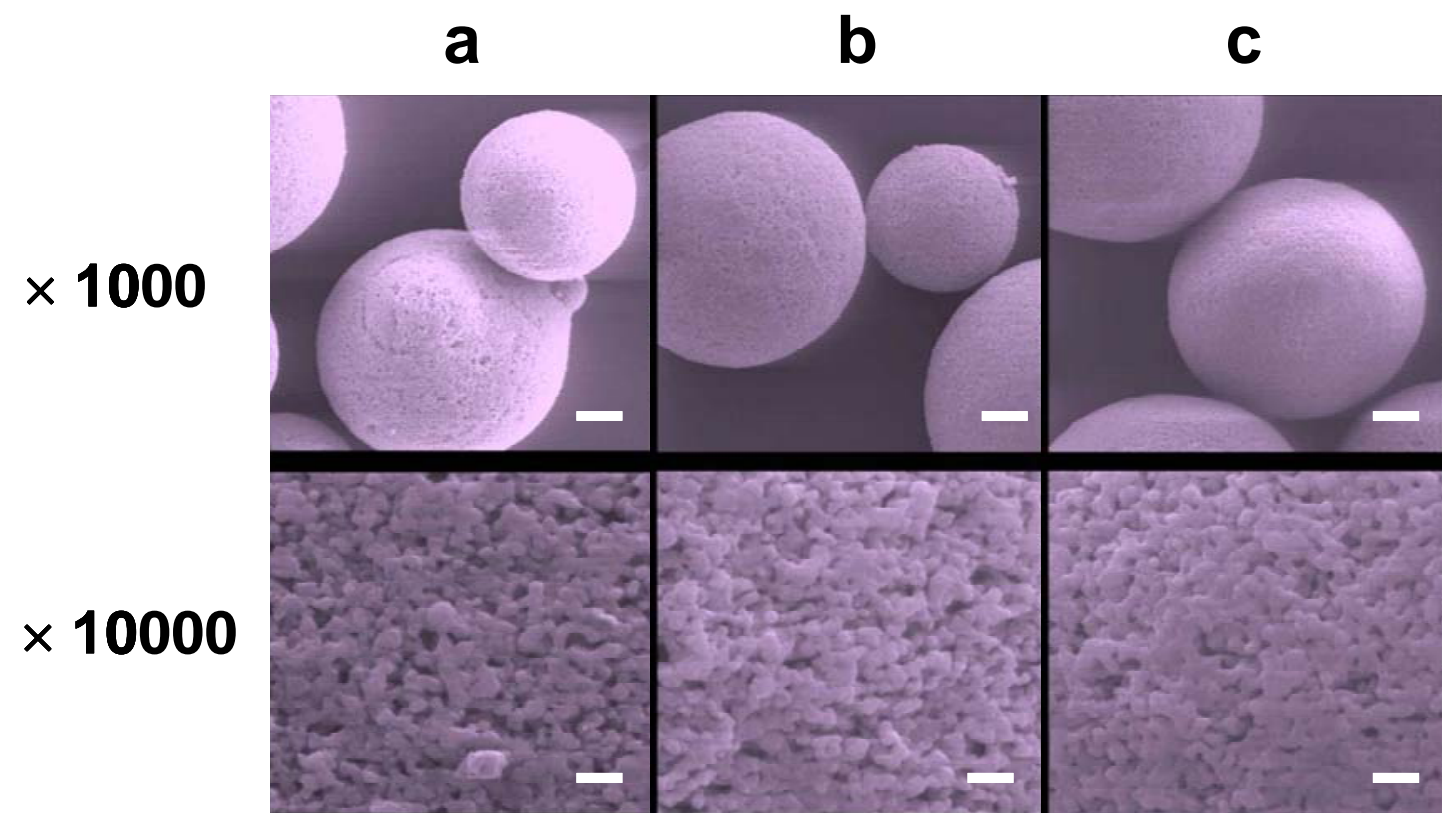

Figure 5 

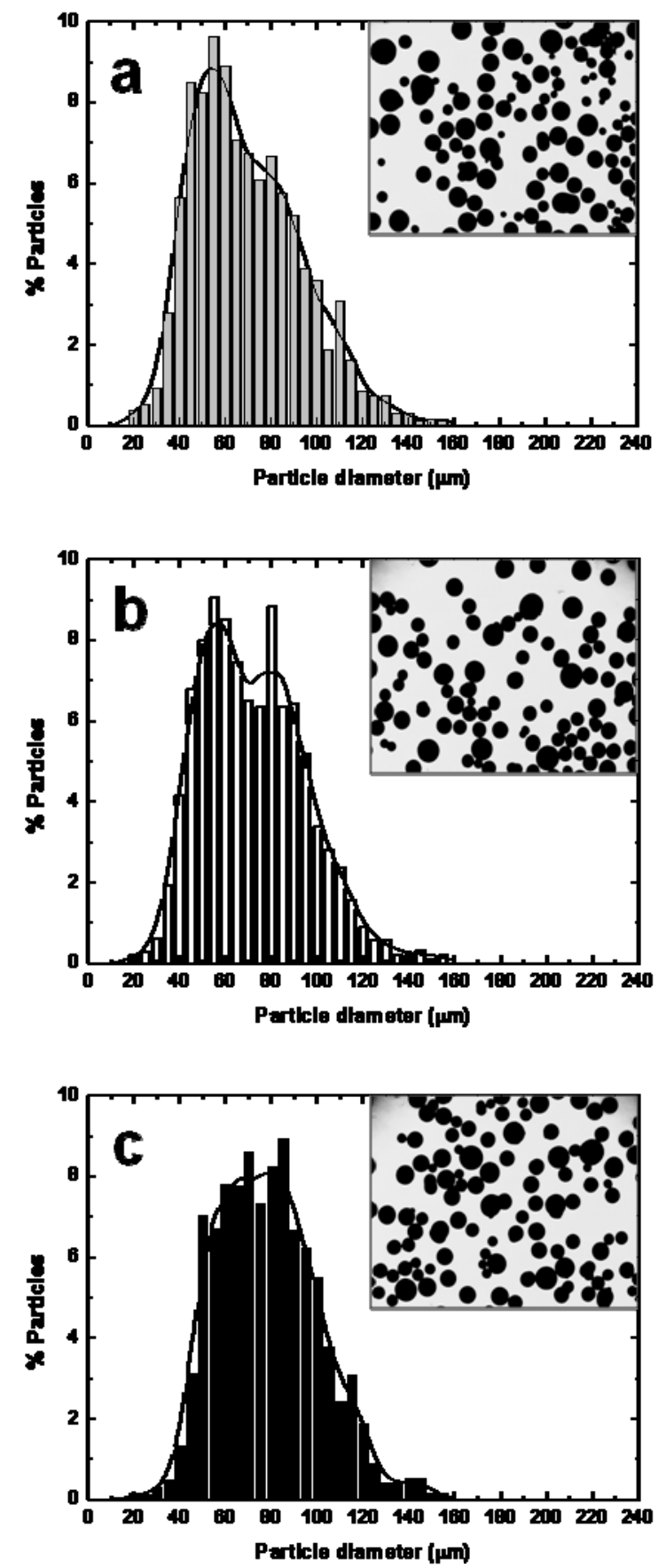

Figure 6 

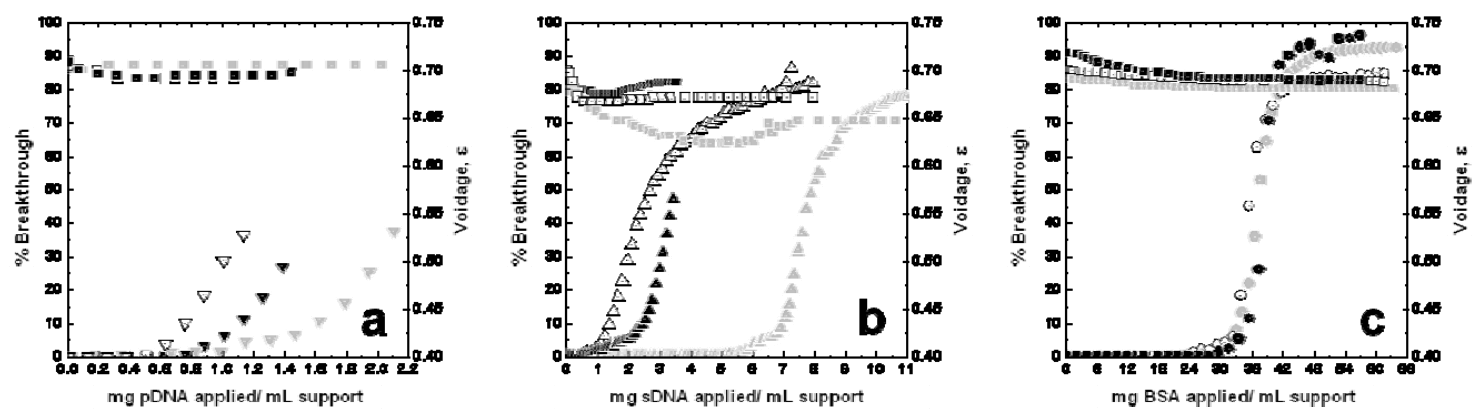

Figure 7 